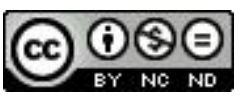

\title{
Educação Matemática na Escola Indígena sob uma Abordagem Crítica*
}

\section{Critical Approach in Mathematical Education in an Indigenous School}

\author{
Luci dos Santos Bernardi** \\ Ademir Donizeti Caldeira***
}

\begin{abstract}
Resumo
Esse artigo busca promover uma reflexão sobre desafios da Educação Matemática na Escola Indígena, tendo como referência o povo Kaingang da Terra Indígena Xapecó, em Ipuaçu (SC), e as possibilidades de inserção, no ambiente de sala de aula, de discussões relacionadas aos papéis desempenhados pela matemática na sociedade indígena. Com esse propósito, apresentamos contribuições da Educação Matemática Crítica a partir de três questões fundamentais: o quadro sociopolítico da educação matemática (globalização e guetorização), competências que deveriam ser associadas à educação matemática (matemacia) e o foreground dos estudantes indígenas. A compreensão de que as práticas e a produção de conhecimentos matemáticos ocorrem em todas as culturas é um dos esteios desse trabalho, que tem aporte teórico na Etnomatemática.
\end{abstract}

Palavras-chave: Educação Escolar Indígena Kaingang. Globalização. Matemacia. Foreground.

\footnotetext{
* Esse artigo faz parte de uma pesquisa de doutorado em desenvolvimento, com um grupo de trabalho colaborativo de professores Kaingang que ensinam matemática, na Terra Indígena Xapecó, em Ipuaçu, SC.

*** Doutoranda do Programa de Pós-Graduação em Educação Científica e Tecnológica da Universidade Federal de Santa Catarina (UFSC). Professora da Área de Ciências Exatas e Ambientais da Universidade Comunitária da Região de Chapecó (UNOCHAPECÓ). Endereço para correspondência: Av. General Osório, 55D, CEP: 89802-213, Chapecó, SC, Brasil.E-mail: lucib@unochapeco.edu.br.

*** Doutor em Educação pela Universidade Estadual de Campinas (UNICAMP). Professor do Departamento de Metodologia de Ensino do Centro de Educação e Ciências Humanas da Universidade Federal de São Carlos (UFSCAR). Endereço para correspondência: Rod. Washington Luis Km 235 (SP-310), CEP: 13.565-905, São Carlos, SP, Brasil.E-mail: miro@ufscar.br.
} 


\begin{abstract}
This article encourages a reflection on the challenges facing mathematical education in an indigenous school in a Kaingang community located in the Xapeco indigenous land area in Ipuacu (SC), and the possibilities of insertion, into the environment of the classroom, of discussions related to the roles played by mathematics in indigenous society. For this purpose, we present contributions from critical mathematical education regarding three fundamental issues: the sociopolitical context of mathematical education (globalization and ghetto-ization), competencies that should be associated with mathematical education (mathemacy) and foreground of indigenous students. The understanding that the practices and the production of mathematical knowledge occur in all cultures is one of the mainstays of this study, which is based on the theoretical foundations of Ethnomathematics.
\end{abstract}

Keywords: Kaingang Indigenous School Education. Globalization. Mathemacy. Foreground.

\title{
1 Introdução
}

A educação escolar indígena brasileira se caracteriza por encaminhamentos distintos nas relações entre o Estado brasileiro e os povos indígenas no Brasil, construindo uma história, em cinco séculos de intervenção, na qual se podem reconhecer duas tendências: a de dominação e a do pluralismo cultural.

A dominação, por meio da integração e homogeneização cultural, teve seu marco inicial no trabalho dos jesuítas, cujo principal objetivo - catequizar os indígenas para que servissem como força de trabalho à coroa portuguesa desencadeou um processo de colonização e escravidão. Posteriormente, as ações tiveram como objetivo integrá-los à sociedade nacional, na busca por uma evolução cultural unilinear, pois os indígenas eram considerados primitivos e atrasados; almejava-se a unificação da religião, da língua e da cultura, negando, assim, a diversidade.

A concretização de uma nova política indigenista, de pluralismo cultural, tem amparo na Constituição brasileira de 1988 (BRASIL, 1988), a qual, pela primeira vez na história, reconhece aos indígenas o direito à prática de suas formas culturais próprias, assegurando sua alteridade cultural.

O texto constitucional é um marco importante no campo educacional, a partir do qual o estado institui uma política dentro dos princípios do respeito à diversidade étnica e cultural, pautada no reconhecimento dos valores e saberes 
transmitidos pelos indígenas ao longo de muitas gerações, garantindo, inclusive, a prática do ensino bilíngue em suas escolas. Assim, cada vez mais, a escola assume a função de mediar esse diálogo cultural com os diferentes povos. De acordo com o Referencial Curricular Nacional para as Escolas Indígenas RCNE/Indígena (BRASIL, 1998) - o cotidiano da maior parte dos povos indígenas, no Brasil, desenrola-se num contexto de tensão entre conhecimentos indígenas e não-indígenas. Essas tensões passam pela escola indígena, fazendoa palco para o diálogo ou conflito entre forças em interação.

Especificamente, para o povo Kaingang da Terra Indígena Xapecó, em Ipuaçu (SC), a educação escolar indígena pode ser um instrumento de fortalecimento das culturas e das identidades indígenas, bem como um caminho para a conquista da desejada cidadania, compreendida, aqui, como direito de acesso aos bens e aos valores materiais e imateriais do mundo contemporâneo; para isso, é necessária a construção de um projeto educacional pelos e para os povos indígenas Kaingang, que atenda aos seus interesses e aspirações. Esse processo de construção requer a participação efetiva e colaborativa do Estado e da sociedade organizada.

Na região de inquérito da Educação Matemática, defendemos a importância de pensar para além da aprendizagem da matemática do povo Kaingang e da matemática institucionalizada na escola indígena, também possibilitar ao estudante conhecer em que circunstâncias tais matemáticas estão sendo aplicadas e compreender como o uso dessas matemáticas pode influenciar na vida de seu povo, o que significa construir um projeto educacional para os indígenas na perspectiva da Educação Matemática com um aporte teórico e metodológico sustentado pela da Etnomatemática ${ }^{1}$ e pela Educação Matemática Crítica.

\section{0 indígena Kaingang do oeste do estado de Santa Catarina}

No Brasil, os povos indígenas conformam duzentos e vinte e dois povos, étnica e socioculturalmente diferenciados, que falam cento e oitenta línguas distintas, organizadas pelos linguistas em três troncos: Tupi, Macro-Jê e Aruak, sendo que algumas línguas não se enquadram em nenhum desses troncos. A diversidade sociocultural e étnica sofreu uma drástica redução ao longo da história

\footnotetext{
${ }^{1}$ Nesse trabalho, etnomatemática será grafada com inicial minúscula quando se tratar de uma matemática contextualizada histórico-culturalmente e, com letra maiúscula, quando se tratar de linha ou programa de pesquisa, resguardando a utilização dada pelos autores em citações e paráfrases.
} 
de colonização, uma vez que havia mais de 1.500 povos, falando mais de 1.000 línguas distintas quando Pedro Alvarez Cabral chegou ao Brasil, em 1500 (LUCIANO, 2006).

A expressão Kaingang aborda grupos indígenas falantes de dialetos de uma mesma língua, filiados ao tronco Jê Meridional, derivado do Macro-Jê. Esse povo ocupou praticamente todas as florestas de pinheiros, compreendendo a região sudeste/sul do atual território brasileiro, e conservaram sua liberdade, nesse território, até meados do século XIX. A partir desse período, desencadeouse um processo de ocupação do território por povos não-indígenas, que marcou profundamente a vida do povo Kaingang, que sempre foi considerado como um obstáculo ao progresso, ora aldeado, ora transferido, às vezes usado como mão de obra barata, outra tantas, simplesmente eliminado.

Nos últimos duzentos anos, ao olharmos a história do contato entre os Kaingang do oeste do Estado de Santa Catarina e as sociedades não-indígenas, é possível compreender as mudanças impostas à dinâmica social e cultural do grupo. Os conflitos sobre território e a repressão no processo de colonização da região promoveram a negação de sua identidade e o apagamento de sua língua, numa tentativa de transformar o indígena em um não-indígena. No entanto, a capacidade de reação e de adaptação desse povo lhe possibilitou a sobrevivência, precisando, para isso, incorporar novos elementos à sua cultura e abandonar outros, de acordo com a necessidade de adaptação, no que se refere aos aspectos sociais, culturais e ambientais. Eles conheceram, enquanto minoria étnica, a dizimação decorrente do contato com os não-indígenas, a perda de seus territórios e dos recursos naturais, bem como de elementos plenos de significado simbólico na cultura de seu povo.

Apesar dessa história de dominação e expropriação vivenciada pelos Kaingang, eles conseguiram chegar ao século XXI mantendo sua identidade e se afirmando enquanto povo capaz de lutar por seus projetos e direitos constitucionais, e pela conquista de cidadania global diferenciada, como nos coloca Nacke e Blomer (2007).

Hoje, a luta desse povo vai para além de recuperar suas terras, pois objetiva preservar sua dignidade, seus valores e sua cultura. O contexto de intensas relações sociais e trocas culturais não permitem a eles viverem como se isso não os afetasse: na vida dos Kaingang da Terra Indígena Xapecó, tradição e contemporaneidade estão lado a lado. Existe uma familiaridade em relação à sociedade de entorno, principalmente, no acesso a bens e a serviços por grande parte da comunidade. Contudo, de acordo com Nötzold (2004, p.3) “os Kaingang 
mantém traços culturais muito fortes, que os diferencia da sociedade envolvente, principalmente referente à concepção de mundo, relação com a natureza, tratamento dispensado às crianças e nas atividades de seu cotidiano".

Como encontrar equilíbrio entre tradição e contemporaneidade? O campo fértil para essa discussão é a escola indígena ${ }^{2}$, lugar onde os povos podem reforçar seus projetos socioculturais e abrir caminhos para o acesso a outros conhecimentos universais, necessários e desejáveis, a fim de contribuírem com a capacidade de responder às novas demandas geradas a partir do contato com a sociedade global. A escola é o espaço de reafirmação das identidades e da construção permanente de autonomia e alteridades, num desafio cotidiano, que busca permitir ao Kaingang de hoje o orgulho de ser nativo e lutar para reconstruir o projeto sociocultural de seu povo, onde possa se reconhecer como indígena Kaingang, fortalecer o sentimento de ser indígena, de sentir-se indígena, ao mesmo tempo em que estabelece diferentes relações com as sociedades de entorno.

\section{0 cotidiano escolar indígena e a etnomatemática}

Pensar na educação escolar indígena é, necessariamente, lançar um olhar sobre sua construção histórica, marcada pela subordinação da diversidade cultural ao projeto de homogeneização que norteou as políticas públicas até a década de 80. A escola foi o espaço para consolidação e disseminação da invisibilidade dessa diversidade, geradora de desigualdades sociais num contexto tensionado entre pluralidade e universalidade, entre o local e o global.

Como primeiro elemento para a reflexão proposta, trazemos a compreensão acerca da cultura, conectada às lutas que estão em jogo no processo de sua apropriação, e sua legitimação nas relações de poder daqueles que a produzem e a reproduzem. O entendimento que damos à cultura é de algo produzido pelos grupos sociais, algo que não está determinado, consolidado e fechado nos seus significados, mas em permanente disputa pela imposição de significados, considerando a noção de poder a ela associada.

No campo da Educação Matemática, propomos que o trabalho de natureza intercultural no contexto escolar indígena considere que as práticas e a

\footnotetext{
${ }^{2}$ A comunidade educacional da Terra Indígena Xapecó é formada por três escolas de Educação Infantil e Educação Básica, que fazem parte do sistema educacional do Estado de Santa Catarina, tendo: 150 alunos no ensino médio; 1.164 no ensino fundamental; 61 professores (Agosto/2010). Entre elas, a Escola Indígena de Educação Básica Cacique Vanhkrê, a primeira escola do país a possibilitar a uma comunidade indígena a conclusão do ensino básico, de forma específica e diferenciada.
} 
produção de conhecimentos matemáticos ocorrem em todas as culturas e têm fecundidade na Etnomatemática, enquanto campo de pesquisa e de ensino.

Nesse sentido, D’Ambrosio (2008) nos chama a atenção para a existência de diferentes etnociências e das suas influências mútuas que criaram a matemática, tal como a conhecemos hoje, revestida de um caráter universal e materializada nos currículos de nossas escolas.

A disciplina denominada matemática é, na verdade, uma Etnomatemática que se originou e se desenvolveu na Europa mediterrânea, tendo recebido algumas contribuições das civilizações indiana e islâmica, e que chegou à forma atual nos séculos XVI e XVII, sendo, a partir de então, levada e imposta a todo o mundo. Hoje, essa matemática adquire um caráter de universalidade, sobretudo devido ao predomínio da ciência e tecnologia modernas, que foram desenvolvidas a partir do século XVII na Europa. (D’AMBROSIO, 2001, p. 28).

A hegemonia do eurocentrismo, inculcada na formação do professor indígena que ensina matemática, dificulta a aceitação de uma história da matemática diferente da divulgada pela tradição ocidental, que compreenda as raízes culturais de seu povo através de seus valores, estilos cognitivos e práticas. A supremacia imposta pelo pensamento ocidental faz dessa única etnomatemática ensinada na escola indígena - ocidental, branca e europeia - denominada de matemática, um fator de ruptura com a dinâmica cultural do povo Kaingang.

Consideramos que, ouvir a voz dos sujeitos desses povos configura uma das buscas da Etnomatemática. Significa que professor e estudante estabeleçam relações entre as diferentes etnomatemáticas: a cultura específica e a cultura globalizante, ou seja, o conhecimento que é tradicional (cultura local) e o conhecimento que é institucional (cultura universal).

A articulação e significação desses dois conhecimentos no cotidiano escolar podem fundamentar-se na Abordagem Etnomatemática ${ }^{3}$ proposta por Knijnik:

Utilizo a expressão Abordagem Etnomatemática, para designar a investigação das tradições, práticas e

\footnotetext{
${ }^{3}$ Gelsa Knijnik (2006) em sua tese "Trabalhadores Sem Terra do Brasil" desenvolve uma Abordagem Etnomatemática, expressão que a autora utilizou em sua atividade de pesquisa, até 1990, para nomear a investigação das concepções, tradições e práticas matemáticas de um determinado grupo social, no intuito de incorporá-las ao currículo como um conhecimento escolar; durante a realização de sua tese, essa conceituação foi sucessivamente reformulada, conduziu a uma especificação conceitual para o contexto de sua pesquisa.
} 
concepções matemáticas de um grupo social subordinado (quanto ao volume e composição de capital social, cultural e econômico) e o trabalho pedagógico que se desenvolve com o objetivo de que o grupo interprete e decodifique seu conhecimento, adquira o conhecimento produzido pela Matemática acadêmica e estabeleça comparações entre o seu conhecimento e o conhecimento acadêmico, analisando as relações de poder envolvidas no uso desses dois saberes. (KNIJNIK, 2006, p. 148).

A abordagem de Knijnik privilegia uma dimensão sociopolítica para a Educação Matemática. No contexto da educação escolar indígena significa conceber o processo educativo pautado na matemática tradicional, do povo Kaingang e na matemática institucional ${ }^{4}$, de forma que, de posse destes dois conhecimentos, a comunidade indígena possa se fortalecer politicamente, tornando-se consciente das diferentes possibilidades de utilização do conhecimento matemático, e das relações de poder envolvidas nesse uso, na busca de alternativas para solucionar conflitos ou crises com os quais se deparam, criando espaço para uma educação crítica.

Entendemos que a construção de uma educação crítica é elemento fundamental para conceber o ensino e a aprendizagem da Matemática ${ }^{5}$ na educação escolar indígena, pois representa uma possibilidade para reagir às desigualdades e contradições que prevalecem na sociedade. De acordo com Skovsmose (2001, p. 101) "uma educação crítica, tanto como prática quanto como pesquisa, deve discutir condições básicas para a obtenção do conhecimento, deve estar a par dos problemas sociais, das desigualdades, da supressão, etc., e deve tentar fazer da educação uma força social progressivamente ativa."

No contexto educacional, a Abordagem Etnomatemática favorece uma Educação Matemática Crítica, à medida que permite aos estudantes refletirem sobre a realidade em que vivem, conferindo-lhes o poder de desenvolver e usar a Matemática de uma maneira emancipatória. Essa possibilidade se constrói dependendo das escolhas que são feitas pelo professor, que são determinantes para o desenvolvimento do processo.

\footnotetext{
${ }^{4}$ Matemática tradicional compreende as tradições e as práticas, com ideias, relações, códigos e símbolos próprios do povo Kaingang e a matemática institucional como disciplina escolar, com ideias, relações, códigos e símbolos universais.

${ }^{5}$ Considerando o termo Matemática como o corpo de conhecimentos tanto específico de uma cultura como aquele denominado universal.
} 


\section{Por uma educação matemática crítica}

A Educação Matemática Crítica - EMC, difundida inicialmente pelos trabalhos realizados por Marilyn Frankenstein e Arthur Powell, nos Estados Unidos, e, posteriormente, publicada nos trabalhos desenvolvidos pelo dinamarquês Ole Skovsmose, representa uma reação ao pressuposto de que todo o desenvolvimento tecnológico ocasiona, consequentemente, um progresso, e pretende inserir no ambiente de sala de aula discussões relacionadas aos papéis desempenhados pela matemática na sociedade.

De acordo com Skovsmose (2010), a EMC refere-se a algumas preocupações (desafios) sobre educação matemática, educação, e sociedade, que tem a ver com:

- Diversidade na sociedade.

- (Falta de) igualdade.

- (Falta de) justiça social.

- (Falta de) autonomia de estudantes.

- (Falta de) autonomia de professores.

- Função socioeconômica da educação matemática.

- Função socioeconômica da matemática.

A EMC é um movimento que dá centralidade em seus debates à necessidade de refletir sobre a matemática que prevalece nos currículos escolares - branca, homogênea, ocidental e linear - trazendo para esses debates temas ligados ao poder, pois leva em consideração os aspectos políticos da educação matemática praticada, estabelecendo perguntas como:

A quem interessa que a educação matemática seja organizada dessa maneira? Para quem a educação matemática deve estar voltada? Como evitar preconceitos nos processos analisados pela educação matemática que sejam nefastos para grupos de oprimidos como trabalhadores, negros, índios e mulheres? (BORBA; SKOVSMOSE, 2001, p. 7).

Segundo Skovsmose (2007), a EMC preocupa-se, sobretudo, com os aspectos políticos da educação matemática, tratando das diversidades e conflitos culturais, questionando o papel social da matemática. Surge como uma reação interna à dominação exercida pela Teoria da Modernização ${ }^{6}$ (daqueles que

\footnotetext{
${ }^{6}$ Tanto a Etnomatemática quanto a Educação Matemática Crítica consistiram em reações ao mesmo processo histórico, denominado por Vithal e Skovsmose (1997) como a Teoria da Modernização. Nesse sentido, colocam que a Etnomatemática começa uma reação partindo de fora das sociedades tecnológicas, respondendo a implicações da Teoria da Modernização em termos de imperialismo cultural, e a EMC tem sua reação começando de dentro, como uma reação interna de uma sociedade altamente tecnológica.
} 
sentiam seus reflexos), esta dominação está relacionada, principalmente, ao poder formatador exercido por essa Matemática, pois na medida em que avançam as inovações tecnológicas, mais complexas se tornam as aplicações dessa Matemática, sendo parte de nossa realidade projetada por meio de modelos matemáticos.

Algumas questões se tornam importantes na análise: Por que são assim construídos os modelos? Quais os pressupostos utilizados para a sua construção? Estarão acessíveis os modelos usados? Os cidadãos têm direitos e deveres, mas será que o seu pleno exercício não está bloqueado pelo poder formatador dessa Matemática? (PAIS; GERALDO; LIMA, 2003).

Além de dificultar a vida democrática, o poder formatador da Matemática dificulta o exercício pleno da cidadania. Skovsmose (2001) defende que uma EMC leva a uma competência democrática que se figura importante para o exercício da cidadania; proporciona poderes sociais, permitindo aos alunos o exercício de julgamentos críticos de decisões sociais e políticas.

Essa Matemática, por sua vez, revestida por um caráter de neutralidade, frequentemente assume a posição de empreendimento humano de estrutura estável e inquestionável. Borba e Skovsmose (2001) reforçam essa ideia, ao afirmar que o conhecimento matemático, dado como pronto e incontestável, tem predominado em muitas de nossas escolas, pelo fato de existir o que eles chamam de ideologia da certeza matemática. Os autores argumentam que:

A ideologia da certeza como uma estrutura de interpretação geral e fundamental para um número crescente de questões que transformam a matemática em uma linguagem de poder. Essa visão da matemática - como um sistema perfeito, como pura, como uma ferramenta infalível se bem usada - contribui para o controle político. (BORBA; SKOVSMOSE, 2001, p. 129).

Segundo os autores, a ideologia da certeza está escondida e implicitamente conectada com poderosas ferramentas matemáticas, e pode ser nefasta para a sociedade em geral, e para a educação matemática em particular. Constitui-se, além disso, num discurso fundamentado na concepção de que "a matemática pode ser aplicada em todo lugar e que seus resultados são necessariamente melhores que aqueles obtidos sem a matemática" (BORBA; SKOVSMOSE, 2001, p. 131). Dessa forma, descarta a possibilidade da matemática ser vista como uma maneira de olhar o fenômeno, um corpo de conhecimentos entre muitos outros, e não o único caminho, superior pela sua 
própria natureza.

Borba e Skovsmose (2001) defendem que uma forma de desafiar a ideologia da certeza é mudar a prática de sala de aula, trazendo para ela um cenário de discussão de natureza caótica, que valorize a relatividade, os pontos de partida provisórios, os diferentes pontos de vista e a incerteza; e ainda, não mais olhar a matemática sob o paradigma do verdadeiro-falso, onde a gramática da matemática encaixa-se no mundo platônico sobre o qual estamos falando em sala de aula.

Os conceitos inicialmente apresentados, o poder formatador da Matemática, a competência democrática e a ideologia da certeza, conduzem a uma reflexão inicial acerca dos desafios da Educação Matemática na Escola Indígena: a eminente necessidade de problematizar o poder formatador da matemática em nossa sociedade, de criar oportunidades para que nossos estudantes possam desenvolver a competência democrática e de enfrentar cotidianamente as afirmações da ideologia da certeza.

Esses conceitos não são tratados de forma isolada na Educação Matemática na Escola Indígena, ao contrário, constituem-se em uma rede de relações e significações vinculada a outros conceitos, como justiça social, poder, globalização, guetorização, matemacia, foreground de estudantes, diálogo, possibilidades, significado, e movimento; segundo Skovsmose (2010), concepções importantes na perspectiva de uma Educação Matemática Crítica, mas que se coadunam com as reflexões da Educação Matemática na Escola Indígena. Trataremos de alguns deles a seguir.

Segundo Skovsmose (2007), a EMC não é para ser entendida como um ramo especial da Educação Matemática, tampouco deve ser identificada como uma metodologia de sala de aula, ou constituída de currículos especiais. Ao contrário, o autor a define em termos de algumas preocupações emergentes: "uma resposta para uma posição crítica da educação matemática" (SKOVSMOSE, 2007, p.73).

Propomos uma questão inicial para refletir sobre esse tema: são de natureza crítica as preocupações dos indígenas em relação à educação escolar e à educação tradicional dos seus povos?

Para o indígena, a escola não é o único lugar de aprendizado; apresentase como uma maneira de organizar alguns tipos de conhecimento e saberes, para serem transmitidos às pessoas por um professor, pois a comunidade possui a sua sabedoria para ser comunicada, transmitida. Vejamos alguns valores e exemplos de mecanismos de educação tradicional dos povos indígenas, mantidos e valorizados até hoje: 
- A família e a comunidade ou o povo são os responsáveis pela educação dos filhos.

- É na família que se aprende a viver bem: ser um bom caçador, um bom pescador.

- Aprende-se a fazer roça, plantar, fazer farinha.

- Aprende-se a fazer canoa, cestarias.

- Aprende-se a cuidar da saúde, benzer, curar doenças, conhecer plantas medicinais.

- Aprende-se a geografia das matas, dos rios, das serras; a matemática e a geometria para fazer canoas, remos, casas, roças, caruri etc.

- Não existe sistema de reprodução ou seleção.

- Os conhecimentos específicos, como o dos pajés, estão a serviço e ao alcance de todos.

- Aprende-se a viver e a combater qualquer mal social, para que não haja na comunidade crianças órfãs e abandonadas, pessoas passando fome, mendigos.

- Alunos e professores de escolas atuais ensinam novos conhecimentos aos antigos pajés, mestres e caciques tradicionais e vice versa. (LUCIANO, 2006, p. 147).

Consideramos que uma educação escolar indígena, que possibilite, no seu cotidiano, o reconhecimento desses valores e mecanismos que os povos indígenas ainda mantêm vivos nas suas formas de educação tradicional, traz em seu bojo uma formação política e uma prática educacional convergente com as preocupações da EMC. Podemos observar isso, examinando alguns valores apontados na educação tradicional dos povos indígenas, como segue:

O primeiro é a noção de diálogo: alunos e professores de escolas atuais ensinam novos conhecimentos aos antigos pajés, mestres e caciques tradicionais e vice-versa. O diálogo supõe troca, os homens se educam em comunhão, mediatizados pelo mundo. "Desta maneira, o educador já não é aquele que apenas educa, mas o que, enquanto educa, é educado, em diálogo com o educando, que ao ser educado, também educa" (FREIRE, 2005, p. 79). A relação dialógica requer outra concepção de homem e de mundo, superando-se a relação vertical, sustentada pelos argumentos de autoridade. O educador passa a ser companheiro do educando em suas relações com eles, no sentido da humanização de ambos.

O segundo refere-se à ideia de democracia: os conhecimentos específicos, como o dos pajés, estão a serviço e ao alcance de todos. 
Propõem uma distribuição justa de serviços sociais na sociedade, oportunidades iguais, direitos e deveres para todos os membros da sociedade.

O terceiro estabelece-se com a noção de justiça social: não existe sistema de reprodução ou seleção; aprende-se a viver e a combater qualquer mal social, para que não haja na comunidade crianças órfãs e abandonadas, pessoas passando fome, mendigos. O conceito de justiça social é relacionado aos conceitos de igualdade e equidade.

As relações com a EMC não se esgotam. Mas, também, não podemos ter a ilusão de que esses (e outros) valores estão de fato presentes na educação tradicional de todos os povos, pois como já apontamos, a dinâmica de alguns povos foi modificada pelo contato com o homem branco, em especial, o povo Kaingang da Terra Indígena Xapecó, que sofreu um intenso processo de desintegração cultural; tampouco, podemos ter a ingenuidade de supor que esses valores sejam esteios para a educação escolar na contemporaneidade. Mas têlos como indicadores demonstra que a formação política é um desejo e uma possibilidade. Queremos, ainda, chamar a atenção para o forte estreitamento entre os valores e movimentos com o conhecimento e preservação da cultura, um dos fundamentos da Abordagem Etnomatemática.

Nesse contexto, assinalamos três questões apresentadas por Skovsmose (2001) que nos ajudam a refletir sobre a Educação Matemática na escola indígena, e as possibilidades de inserção, no ambiente de sala de aula, de discussões relacionadas aos papéis da Matemática na sociedade indígena: sobre o quadro sociopolítico da educação matemática; sobre competências que deveriam ser associadas à educação matemática e sobre os estudantes.

\subsection{O quadro sociopolítico da educação matemática - globalização e guetorização}

A EMC está relacionada aos distintos papéis possíveis que a educação matemática pode ou poderia desempenhar em um contexto sociopolítico particular. Segundo Skovsmose (2007) a EMC está ligada a como a educação matemática pode ser estratificadora, selecionadora, determinadora e legitimadora de inclusões e exclusões, como também, ligada a rotas diferentes e possíveis que o processo de globalização pode ou não tomar.

Qual a ideia que temos da globalização? Não é um fenômeno recente, já aconteceu nos séculos XV e XVI, durante a expansão marítima e comercial. Esse processo foi marcado pela invasão em diferentes aspectos: geográfica, 
social, econômica e cultural, como ocorreu no Brasil em relação aos povos indígenas. A chegada do homem branco repercutiu em profundas mudanças na vida dos povos que aqui habitavam, levando-os quase ao extermínio. O indígena brasileiro conheceu o significado da colonização e da dominação, no sentido como se refere Alfredo Bosi (1994 apud NASCIMENTO, 2001), em que colonizar procura ocupar, cultivar, submeter, buscando, sempre, um novo chão onde possa exercer seus efeitos; teve sua cultura desprezada e inferiorizada, sentindo-se ocupado, invadido, dominado, sem condições para reagir, idealística e materialmente, procurando, então, imitar o colonizador e identificar-se com ele.

Atualmente, a globalização apresenta-se de forma atraente ao dar a ideia de que proporciona a eliminação de fronteiras, incluindo uma sensação de estar junto e poder compartilhar nosso mundo com os outros, como se todo o globo se tornasse uma grande comunidade. No entanto, há aspectos positivos e negativos: "Para alguns, é algo que terminaremos por fazer se desejamos ser felizes; para outros, é a causa de nossa infelicidade. Para todos, entretanto, é o inevitável destino do mundo, um processo irreversível...". (BAUMAN, 1998 apud SKOVSMOSE, 2005, p. 115). O autor complementa: a globalização divide tanto quanto une, e as causas da divisão são as mesmas que uniformizam o globo.

Dessa maneira, falar de globalização significa, também, falar de guetorização, pois assim como ela elimina limites e fronteiras, estabelece novos limites e novas fronteiras, provoca o desenvolvimento e o subdesenvolvimento econômico, é responsável por um processo de inclusão e exclusão social que atinge todo o mundo. Para Skovsmose (2008) podemos pensar a formação de guetos como um tipo de efeito colateral da globalização, que também faz parte do processo, ou seja, globalização significa, também, a formação de guetos.

Assim, globalização significa conhecer diferentes culturas, tradições e lugares. Globalização significa um privilégio por se poder ser um cidadão do mundo. A guetorização, por sua vez, significa exatamente o contrário. Ela significa estar impedido de se mudar. Pessoas guetorizadas são pessoas imobilizadas. A questão é que, simplesmente, essas pessoas não são necessárias. [...] Como Bauman enfatiza: "Guetos e prisões são duas variedades de estratégias de "fixação do indesejável no chão' do confinamento e da imobilização". (BAUMAN, 2001, p. 120, apud SKOVSMOSE, 2005, p. 125). 
A forma como a sociedade brasileira conduziu historicamente sua relação com os indígenas, e o papel social que lhe atribui, não sentindo a necessidade de seu trabalho e não se preocupando com suas demandas, contribuiu para identificar o indígena enquanto um dos sujeitos indesejáveis, confinado e imobilizado nas terras demarcadas. Na região da terra Indígena Xapecó, a luta que culminou com a desapropriação de terras dos agricultores influenciou fortemente na construção da imagem do indígena como um sujeito improdutivo, acomodado, dependente de recursos do governo para sobreviver; existe, ainda, um clima de hostilidade e de rejeição em algumas comunidades. Castells (1996) emprega o termo Quarto Mundo, criado por processos globalizados de exclusão social, econômica e política. Os indígenas fazem parte desse Quarto Mundo, constituído por sujeitos que não tem função na economia globalizada.

Para Skovsmose (2008), globalização e formação de guetos têm a ver com escolaridade, educação e aprendizagem em geral. Basta pensarmos na escola que funciona nas fronteiras entre o Quarto Mundo e o restante da sociedade, entre uma Terra Indígena e o restante da sociedade: ela pode ser uma alavanca para adentrar a ordem social, mas, também pode transformar-se no algoz que exclui os indivíduos da rede global. A educação matemática faz parte dos processos de globalização e guetorização, e devemos refletir sobre como a matemática opera nesse contexto, o que, certamente, não está explicito nos processos educacionais.

Em relação à escola indígena, é importante que reflitamos sobre o que acontece nessas escolas: Que tipo de oportunidade elas oferecem aos estudantes indígenas? O que a educação matemática pode significar para esses estudantes? Qual a expectativa da comunidade em relação à escola? Que parâmetros e modelos são utilizados? Ou, como pensar e inserir práticas educacionais que atendam aos projetos socioculturais dos povos indígenas, concorrentes com os modelos e as perspectivas de projetos globais de escola e de educação homogeneamente colocados a serviço do mercado? Ela está voltada para os indivíduos ou para os povos historicamente excluídos e oprimidos?

Uma educação matemática crítica deve considerar tanto as questões educacionais superiores quanto as básicas. Skovsmose (2007) defende que é importante considerar a educação matemática da perspectiva da globalização, incluindo todas as características atraentes que a globalização pode incluir, mas, também é igualmente importante considerar o que a educação matemática poderia significar para os potencialmente excluídos. 


\subsection{Competências que deveriam ser associadas à educação matemática - Matemacia}

Na especificidade da educação escolar indígena, percebe-se que o ponto fundamental é ter resgatado o conceito mais amplo de educação - a concepção original de relacionar a prática educacional com a prática da vida. Para isso, são necessários novos parâmetros que se contraponham a mais de cem anos de um modelo de sistema escolar desconectado dos métodos próprios de aprendizagem das diferentes culturas tradicionais.

De acordo com Luciano (2006), em termos de futuro, essa perspectiva é vista como algo capaz de suprir as necessidades emergentes da realidade histórico-cultural dos povos indígenas do Brasil, sendo que as escolas indígenas diferenciadas:

[...] pautam suas ações e estratégias de transmissão, produção e reprodução de conhecimentos na proposta de possibilitar às coletividades indígenas a recuperação de suas memórias históricas, a reafirmação de suas identidades étnicas, a valorização de suas línguas, tradições e ciências, a defesa de seus territórios e outros direitos básicos, além de lhes dar acesso adequado às informações e aos conhecimentos técnicos e científicos da sociedade global, necessários à garantia e à melhoria da vida pós-contato. (LUCIANO, 2006, p. 159).

Assim, no âmbito da educação matemática, para o estudante Kaingang é necessária a posse dos dois tipos de conhecimentos - matemática tradicional do seu povo e matemática institucionalizada - para que possa analisar as relações de poder envolvidas no uso deles na busca de alternativas para solucionar conflitos ou crises emergentes. Trata-se de pensar na educação matemática indígena com o propósito de potencializar o estudante à luz do cenário de sua cultura seu contexto particular - uma educação matemática para o empowerment ${ }^{7}$.

Identificar o potencial para propiciar o empowerment é uma importante preocupação da EMC. Na visão de Skovsmose (2008, p. 122) "Muitos termos foram cunhados para ressaltar esse potencial, como literacia matemática, matemática para a justiça social e numeramento. Eu, no entanto, adoto o

\footnotetext{
${ }^{7}$ Em virtude da riqueza de significados da palavra empowerment (dar poder a; ativar a potencialidade criativa; desenvolver a potencialidade criativa do sujeito; dinamizar a potencialidade do sujeito), em Skovsmose (2001), os tradutores optaram por utilizar a palavra no original e em itálico. Skovsmose também utiliza o termo assim, quando apresenta seus trabalhos em português.
} 
termo matemacia ${ }^{8}$ para indicar o caráter 'crítico' da educação matemática”. Segundo o autor, foram feitas muitas propostas de possíveis significados para literacia matemática, numeramento, matemacia etc.; matemacia pode significar coisas diferentes, dependendo da posição que o sujeito ou o grupo ocupa neste mundo globalizado e cheio de guetos. Skovsmose (2008, p. 123) se restringe a "ilustrar o significado da matemacia apontando como noções de confiabilidade e de responsabilidade podem ser tratadas no âmbito da educação matemática”.

A primeira proposta alerta para o fato das descrições matemáticas conferirem uma inquestionável confiabilidade a qualquer informação; a questão da responsabilidade trata das ações que são realizadas a partir dos dados em que confiamos.

A noção de matemacia é complexa e não pode ser capturada em uma única definição, de forma que não há receitas para estruturar uma prática que deva apoiar o desenvolvimento da matemacia. Para Skovsmose (2008), tratar de questões como confiabilidade e responsabilidade representa uma sugestão de como articular preocupações com o empowerment e desenvolver uma educação matemática com uma dimensão crítica. Devemos, ainda, observar que essas duas questões são de interesse tanto para as práticas básicas quanto para as práticas tecnológicas complexas.

Para Skovsmose (2008) a matemacia se refere à habilidade de lidar com noções matemáticas, de aplicar tais noções em diferentes contextos e de refletir sobre o resultado de tais aplicações. Destacamos, então, a necessidade da construção de campos reflexivos que possibilitem a discussão sobre os critérios utilizados na construção dos conceitos matemáticos tradicionais e institucionalizados, percebendo que: os resultados matemáticos não são neutros - dependem de seus processos de produção - tornando-se imperativo analisar as relações de poder envolvidas no uso dos conceitos, na busca de alternativas para solucionar um problema. Novamente, as questões de confiabilidade e de responsabilidade como meios de articular preocupações com empowerment e com vistas em uma educação matemática com uma dimensão crítica.

$\mathrm{Na}$ construção histórica da relação que o povo Kaingang estabeleceu com a sociedade nacional, bem como nas relações atuais, é possível identificar inúmeras situações e problemas que ilustram as consequências da confiabilidade e da responsabilidade na produção e utilização de dados, como por exemplo: no

\footnotetext{
${ }^{8}$ Em Skovsmose (2001), o autor utiliza o termo matheracy traduzido como alfabetização matemática. D'Ambrósio também utiliza o termo matheracy em vários de seus trabalhos sobre Etnomatemática, com o mesmo significado.
} 
processo de demarcação de terras, na proteção ambiental e territorial, nos dados veiculados pelo governo acerca de investimentos na educação e na saúde indígenas, na administração de recursos destinados a eles, no cotidiano de negociações com diferentes empresas, órgãos ou personagens políticos, na prestação de serviços.

Os Kaingang mostram-se conscientes, no sentido de ver a si mesmos como são afetados pelos processos políticos, mas não se veem como possíveis participantes nesse processo. Propiciar o empowerment de seus estudantes pode abrir caminhos e marcar um novo tempo para esse povo, "onde a escola, um dos principais instrumentos usados durante a história do contato para descaracterizar e destruir as culturas indígenas, possa vir a ser um instrumental decisivo na reconstrução e na afirmação das identidades e dos projetos coletivos de vida" (LUCIANO, 2006, p. 148).

Portanto, ao oportunizar o desenvolvimento da dimensão técnica e da dimensão sociopolítica da matemacia - ampliar a compreensão da matemática e de sua aplicação, bem como proporcionar discussões e reflexões sobre seu uso - é dada a condição para que o indígena, conhecedor dos problemas que afligem seu povo e consciente da importância da sua participação na comunidade, consiga posicionar-se criticamente e atuar nos processos políticos pelos quais são continuamente afetados.

\subsection{0 foreground dos estudantes indígenas}

Refletir sobre uma educação matemática que privilegia a diversidade cultural dos estudantes, como na perspectiva da Abordagem Etnomatemática, nos leva a investigar os processos de exclusão associados com o ensino e a aprendizagem da matemática em relação a determinados grupos de estudantes, neste caso, o grupo de estudantes indígenas Kaingang.

Skovsmose, Alro e Valero (2008) colocam que os indígenas do Brasil, mediante a demarcação de Terras Indígenas, podem experimentar uma posição de fronteira ${ }^{9}$ com referência a, no mínimo, duas culturas diferentes. De um lado, preservam algumas de suas tradições e modos de vida, mesmo que constantemente em perigo de ser invadido por interesses do capitalismo; de

\footnotetext{
${ }^{9}$ A metáfora fronteira tem sido utilizada na investigação que tem a ver com a diversidade cultural. É definida pelos autores como um espaço de intercâmbio individual em que se negocia o significado das diferenças. Uma posição de fronteira é, portanto, uma situação relacional na qual os indivíduos encontram ambientes sociais e chegam a um acordo com as múltiplas escolhas que a diversidade cultural disponibiliza a eles (SKOVSMOSE; ALRO; VALERO, 2008).
} 
outro, os indígenas são conscientes dos poderes da civilização ocidental, por exemplo, em termos de melhoramento das condições de vida de seu povo. Nesse contexto, os autores enfatizam uma questão importante: de que maneira encontrar uma posição de fronteira nos desejos dos estudantes em aprender? Apontam, então, que os motivos para aprender estão relacionados com os antecedentes da pessoa, com o seu background ${ }^{10}$ cultural, e a mesma situação se passa com o foreground ${ }^{I I}$. Os antecedentes têm a ver com as raízes culturais e sociopolíticas de um individuo ou grupo; por foreground de uma pessoa, Skovsmose $(2006,2010)$ entende as oportunidades que a situação social, econômica, política e cultural proporciona a ela, porém, não as oportunidades como elas poderiam existir em qualquer forma objetiva, mas como essas oportunidades são percebidas por uma pessoa.

Dessa forma, para um estudante indígena que vive em uma posição de fronteira, o background, o foreground e as relações estabelecidas entre eles podem, facilmente, ser estruturados por prioridades e possibilidades conflituosas, passíveis de influenciar a maneira como alguns estudantes veem o significado na educação.

Significado é uma importante noção em educação matemática. Skovsmose assinala: "eu vejo significado como um aspecto de atos e educação significativa é aquela em que os estudantes são convidados a ocupar-se em atos de aprendizagem significativa. Significado é produzido pelos educandos, por cooperação entre os educandos e entre os educandos e professores" (SKVOSMOSE, 2006, p. 113).

Considerando as reflexões que fizemos, nesse trabalho, acerca da perspectiva da educação escolar indígena e suas relações com a Abordagem Etnomatemática, é fundamental considerar o background dos estudantes indígenas para a construção de uma educação matemática significativa, mas não deve ser um limitador quando o significado em educação matemática indígena é discutido. É necessário, também, considerar seu foreground, um importante elemento no entendimento das ações de aprendizagem dos estudantes, pois intencionalidade é um elemento básico em qualquer ação. A ação é movida pelas intenções, as quais manifestam expectativas, aspirações e esperanças. $\mathrm{O}$

\footnotetext{
${ }^{10}$ Frente às dificuldades de traduzir, neste contexto, a palavra background (experiências anteriores que justificam fatos/ações posteriores) em Skovsmose (2006), os tradutores optaram por manter a palavra em inglês e itálico.

${ }^{11}$ Frente ao valioso e complexo significado da palavra foreground no texto/contexto (possibilidades de futuro, planos futuro), em Skovsmose (2006), os tradutores optaram por manter a palavra em inglês e itálico.
} 
que os indígenas pensam acerca de seus futuros? Quais as aspirações em relação ao trabalho, sustento, continuação de estudos? Em que medida aprender matemática tem significado para o seu futuro? Como um estudante indígena, que vive em uma posição de fronteira, consegue perceber seu background e seu foreground?

A reflexão sobre essas questões tem como base o passado e o presente de um povo historicamente excluído e oprimido, nos valores e saberes de sua cultura e das experiências vividas, porém a ação só é mobilizada, e produz significado, pelo olhar que eles têm lançado ao futuro. Skovsmose (2006) explicita essa ideia quando afirma que significado não representa o passado e o presente, representa, também, o futuro. E, ainda:

Concebemos o significado e a significância das atividades de aprendizagem matemática relacionadas aos antecedentes e às expectativas dos estudantes quanto ao seu futuro. Portanto, consideramos de grande importância investigar o foreground dos estudantes, visando compreender qual motivação eles têm de aprender algo. Para estudantes em posição de fronteira, esse desejo de aprender poderia revelar-se numa trama de complexidade que incluiria conflitos e dilemas [...]. (SKOVSMOSE; ALRO; VALERO, 2008, p. 9).

Produção de significados inclui, então, motivos, perspectivas, anseios, esperanças; têm a ver com as relações entre as atividades na sala de aula e o cotidiano, o background e as experiências dos estudantes; tem a ver, também, com as relações entre as atividades na sala de aula e oforeground dos estudantes, pois se o estudante não puder ver qualquer perspectiva no que ele está fazendo, não podemos esperar qualquer participação significativa dele; tem a ver com as escolhas que um estudante indígena, que vive em uma posição de fronteira, faz sobre as prioridades e as possibilidades que, repetimos, são conflituosas, levando em conta o background, o foreground e as relações estabelecidas entre eles.

\section{Algumas considerações}

Para pensarmos sobre a Educação Matemática na escola indígena Kaingang é certamente necessário compreendermos como esta pode contribuir com aquela comunidade, para garantir o seu espaço na sociedade brasileira majoritária contemporânea, sem necessidade de abrir mão do que lhe é próprio: as culturas, as tradições, os conhecimentos e os valores. Nesse propósito, 
acreditamos que a Educação Matemática pode oportunizar ao povo Kaingang fazer ouvir sua voz, tendo sua forma de matematizar e interpretar a realidade, valorizada, pesquisada, registrada e sistematizada dentro da escola, bem como tenha o acesso à matemática institucionalizada, sendo isso considerado pelos povos indígenas como elemento fundamental na formação escolar.

Entendemos que esse trabalho tem fecundidade nos pressupostos da Abordagem Etnomatemática, enquanto campo de investigação e de ação pedagógica, na medida em que cria condições para que, ao interpretar e decodificar seu conhecimento matemático tradicional e adquirir o conhecimento produzido pela matemática institucional, a comunidade indígena possa estabelecer comparações entre eles, considerando as relações de poder envolvidas nos usos desses conhecimentos.

No contexto educacional, queremos destacar a importância do povo indígena Kaingang, através de sua comunidade escolar, discutir os papéis desempenhados pela Matemática na sociedade indígena, e compreender as diferentes possibilidades de seu desenvolvimento e de sua utilização de forma emancipatória.

Considerando que precisamos saber apreender, com sensibilidade, as responsabilidades que nos cabem acerca da função sociopolítica da matemática, trazemos para essa discussão o aporte teórico da EMC, cujos desafios representam uma resposta para a posição crítica da educação matemática.

Nesse contexto, refletindo sobre as possíveis contribuições da EMC para uma reação às contradições e desigualdades sociais enfrentadas pelo povo indígena Kaingang, apresentamos três questões fundamentais:

Na primeira, o quadro sociopolítico da educação matemática; chamamos a atenção para a importância de a comunidade educacional indígena refletir sobre os distintos papéis que a educação matemática pode desempenhar no contexto sociopolítico do povo Kaingang: como a Matemática opera nesse contexto? Qual a função que a escola indígena vem desempenhando? Para um povo que, por não ter uma função valorizada na economia globalizada, está confinado e imobilizado nas terras demarcadas, guetos criados por processos globalizados de exclusão social, o cotidiano da escola precisa abrir caminhos para um novo processo educativo emancipatório.

Sobre competências, a segunda questão, a EMC nos propõe pensar a educação matemática indígena com o propósito de potencializar o estudante à luz do cenário de sua cultura - seu contexto particular, uma educação matemática para o empowerment. Destacamos esse potencial com a noção de matemacia, 
que se refere ao indígena desenvolver a habilidade de lidar com noções matemáticas, de aplicar tais noções dentro e fora da terra indígena e de refletir sobre o resultado de tais aplicações, questionando os critérios utilizados na construção de tais noções e o significado do resultado encontrado. Confiabilidade e responsabilidade representam esteios para esse potencial, numa dimensão de educação crítica.

Por fim, trazemos a questão dos estudantes. Pensar em uma educação matemática que confere atenção à diversidade cultural dos estudantes indígenas Kaingang nos leva a investigar os processos de exclusão associados com o ensino e a aprendizagem da Matemática, para os quais é necessário considerar que os motivos para aprender estão relacionados com o background e com o foreground desses estudantes, pois devemos atentar não somente ao seu solo pretérito, mas, também, aos seus horizontes futuros.

Uma educação emancipatória tenta adicionar algo, talvez quase infinitesimal, no foreground do estudante indígena; essas adições são importantes, se o foreground de um estudante ou do grupo de estudantes kaingang for arruinado, arruína-se, facilmente, a produção de significados, o que torna impossível a sua mobilização em sala de aula, permitindo que os processos de exclusão tornem-se parte da prática na escola indígena.

Para finalizar, queremos salientar que refletir sobre as três questões apresentadas é uma tarefa de cunho sociopolítico, importante e urgente. Cabe, então, a cada participante da comunidade escolar indígena assumir o papel de protagonista na busca de mudanças, e, assim, começar a escrever uma história diferente, de alteridade e de emancipação.

\section{Referências}

BRASIL. Presidência da República, Casa Civil. Constituição da República Federativa do Brasil de 1988. Outubro, 1988.

BRASIL Ministério da Educação e do Desporto, Secretaria de Educação Fundamental. Referencial curricular nacional para as escolas indígenas. Brasília: MEC/SEF, 1998.

D’AMBROSIO, U. P. A educação matemática e etnomatemática. Teoria e prática da educação, Maringá, v. 4, n. 8, p. 15 - 33, jun. 2001.

D'AMBROSIO, U. P. Etnomatemática e história da matemática. CONGRESSO

BRASILEIRO DEETNOMATEMÁTICA, 3., 2008, Niterói, RJ. Anais... Niterói: Editora da UFF, 2008. 
BORBA, M.; SKOVSMOSE, O. A ideologia da certeza em matemática. In: SKOVSMOSE, O. A educação matemática crítica: a questão da democracia. Campinas: Papirus, 2001. p. 127 - 148. (Coleção Perspectivas em Educação Matemática).

CASTELLS, M. Fluxos, redes e identidades: uma teoria crítica da sociedade informacional. In: CASTELLS, M. et al. Novas perspectivas críticas em educação. Porto Alegre: Artes Médicas, 1996. p. 04 - 32.

FREIRE, P. Pedagogia do oprimido. 41. ed. Rio de Janeiro: Paz e Terra, 2005.

KNIJNIK, G. et al. Etnomatemática, currículo e formação. Santa Cruz do Sul: EDUNISC, 2006.

LUCIANO, G. dos S. O índio brasileiro: o que você precisa saber sobre os povos indígenas no Brasil de hoje. Brasília: Ministério da Educação, Secretaria de Educação Continuada, Alfabetização e Diversidade; LACED/Museu Nacional, 2006. (Coleção Educação para Todos).

NASCIMENTO, E. S. do. Há vida na história dos outros. Chapecó: Argos, 2001. (Coleção Debates).

NACKE, A. BLOMER, N. M. S. A área indígena Kaingang no oeste catarinense. In: NACKE, A. et al. (Org.). Os Kaingang no oeste catarinense: tradição e atualidade. Chapecó: Argos, 2007. p. 43 - 78.

NÖTZOLD, A. L. O ciclo de vida kaingang. Florianópolis: Imprensa Universitária da UFSC, 2004.

PAIS, A.; GERALDO, H.; LIMA, V. Educação matemática crítica e etnomatemática: conflitos e convergências, 2003. Disponível em: < http://www.educ.fc.ul.pt/docentes/ jfmatos/mestrados/fcul/aem/aem_ese/diversos_2003.doc>. Acesso em: 22 ago. 2010.

SKOVSMOSE, O. Educação Matemática crítica: a questão da democracia. Campinas: Papirus, 2001. (Coleção Perspectivas em educação Matemática).

SKOVSMOSE, O. Guetorização e globalização: um desafio para a educação matemática. Zetetiké, Campinas, v.13, n.24, p. 113-142, jul./dez. 2005.

SKOVSMOSE, O. Foreground dos educandos e a política de obstáculos para aprendizagem. In: RIBEIRO, J. P. M. et al (Orgs.). Etnomatemática: papel, valor e significado. 2.ed. Porto Alegre: Zouk, 2006. p. 103 - 122. 
SKOVSMOSE, O. Educação crítica. Incerteza, matemática, responsabilidade. São Paulo: Cortez, 2007.

SKOVSMOSE, O. Desafios da reflexão em educação matemática crítica. Campinas: Papirus, 2008. (Coleção Perspectivas em Educação Matemática).

SKOVSMOSE, O. Convite para educação matemática crítica: educação matemática, cultura e diversidade. In: ENCONTRO NACIONAL DE EDUCAÇÃO MATEMÁTICA/ ENEM, 10., 2010, Salvador, BA. Anais... Salvador: SBEM, 2010.

SKOVSMOSE, O.; ALRO, H.; VALERO, P. Antes de dividir, se tiene que sumar: "entrevistar" porvenires de estudiantes indígenas. Revista Latinoamericana de Etnomatematica, San Juan de Pasto, CO, v. 1, n. 2, p. 111 - 136, ago. 2008.

VITHAL, R.; SKOVSMOSE, O. The end of innocence: a critique of 'ethnomathematics'. Educacional Studies in Mathematics, New York, USA, v. 34, n.02, p. 131 - 147, nov. 1997.

Submetido em Março de 2011. Aprovado em Julho de 2011. 

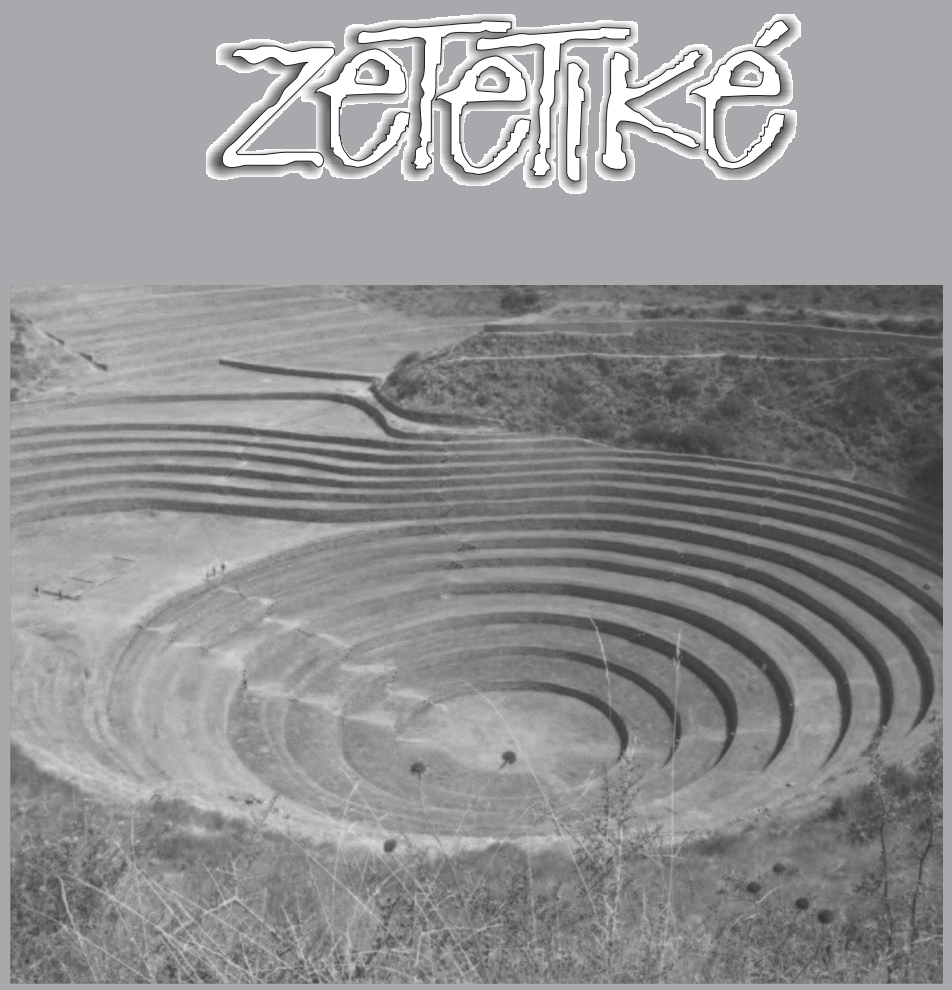

ISSN 0104-4877 